\title{
OPEN Quantitative proteomics analysis of glioblastoma cell lines after IncRNA HULC silencing
}

\author{
Shan $\mathrm{Ye}^{1}$, Jing Wu${ }^{2,3}$, Yiran Wang ${ }^{1}$, Yuchen $\mathrm{Hu}^{1}$, Tiantian Yin ${ }^{1} \&$ Jie $\mathrm{He}^{1,2,3 凶}$
}

Glioblastoma multiforme (GBM) is a life-threatening brain tumor. This study aimed to identify potential targets of the long noncoding RNA (InCRNA) HULC that promoted the progression of GBM. Two U87 cell lines were constructed: HULC-siRNA and negative control (NC). Quantitative real-time PCR (qRT-PCR) was performed to validate the transfection efficiency of HULC silencing vector. Mass spectrometry (MS) was used to generate proteomic profiles for the two cell lines. Gene Ontology (GO) and Kyoto Encyclopedia of Genes and Genomes (KEGG) pathway enrichment analyses were performed to distinguish HULC-related genes and pathway mapping. Colony formation, Transwell, and woundhealing assays were used to investigate the functional effects of HULC knockdown on GBM. We identified 112 up-regulated proteins and 24 down-regulated proteins from a total of 4360 quantified proteins. GO enrichment illustrated that these proteins were mainly involved in organelle structure, catalysis, cell movement, and material metabolism. KEGG pathway analysis indicated that some of these proteins were significantly enriched in tight junction, metabolic pathways, and arachidonic acid metabolism. In vitro experiments demonstrated that HULC knockdown inhibited GBM cell proliferation, invasion, and migration. Our KEGG analyses revealed that PLA2G4A was a shared protein in several enriched pathways. HULC silencing significantly down-regulated the expression of PLA2G4A. Knockdown of HULC changed the proteomic characteristics of GBM and altered the behaviors of GBM cells. Specifically, we identified PLA2G4A as an HULC target in GBM. This study provides a new perspective on the mechanisms and potential drug targets of GBM treatment.

Glioblastoma multiforme (GBM) is the most common central nervous system (CNS) tumor in adults, characterized by a highly malignant aggressive behavior ${ }^{1}$. At present, the standard treatment for GBM includes surgery, radiotherapy, and chemotherapy since targeted therapy performs poorly. Although some new treatments have been developed, such as photodynamic therapy and immunotherapy ${ }^{2,3}$, their efficacy needs to be further evaluated. Disappointingly, even with treatment, GBM patients have a poor prognosis. According to a research in the United States, the 1-year survival rate of GBM patients is approximately $40.2 \%$, and the 5-year survival rate is only $5.6 \%{ }^{4}$. Therefore, there is an urgent need to investigate the underlying pathology of GBM to identify suitable biomarkers that can facilitate early detection and diagnosis, as well as further improve treatment and prognosis.

Long non-coding RNAs (lncRNAs) are described as a family of RNAs that are more than 200 nucleotides in length and harbor different functions according to their subcellular localization. LncRNAs are primarily involved in gene regulation through their interaction with other RNAs or proteins, including transcriptional regulation, post-transcriptional regulation, and epigenetic regulation ${ }^{5}$. Increasing evidence supports that lncRNAs play a vital role in tumorigenesis and progression.

The lncRNA HULC was first discovered in liver cancer tissues by Panzitt et al. ${ }^{6}$. It was later discovered that HULC could promote tumor growth as a $\operatorname{lncRNA}{ }^{7}$. Several studies have also reported that HULC was highly expressed in other tumors, such as gastric cancer, colon cancer, and ovarian cancer. Investigation of the common underlying mechanisms of HULC in different cancers is ongoing ${ }^{8-10}$. Yan et al. suggested that over-expression of HULC might be utilized as a reference index for poor prognosis of $\mathrm{GBM}^{11}$. However, there are only a few studies that have focused on HULC's mechanistic role in GBM ${ }^{12}$.

Proteomics has recently been widely used to identify new tumor biomarkers ${ }^{13-15}$. Mass spectrometry (MS) is the fastest growing, most dynamic, and promising technology in proteomics research. Liquid chromatography

\footnotetext{
${ }^{1}$ Anhui Provincial Hospital Affiliated to Anhui Medical University, Hefei, China. ${ }^{2}$ Department of Pathology, The First Affiliated Hospital of USTC, Hefei, China. ${ }^{3}$ Department of Pathology, Anhui Provincial Cancer Hospital, Hefei, China. ${ }^{\varpi}$ email: hejie23@ustc.edu.cn
} 
coupled with MS (LC-MS) is considered an effective tool in the discovery and verification of disease biomarkers due to its high sensitivity, precision, accuracy, and strong quantitative capability ${ }^{16}$.

In this study, we constructed stable HULC knockdown cell lines to verify the effect of HULC silencing in vitro. Combining highly sensitive quantitative technology with bioinformatics analysis, our study systematically identified differentially expressed proteins and discovered the potential mechanism by which the lncRNA HULC affects GBM tumor growth. Our results provide new insights into the targets involved in GBM pathogenesis, providing a theoretical basis for targeted GMB therapy.

\section{Results}

qRT-PCR detection of HULC expression in two stably-transfected cell lines. The relative expression of HULC in both HULC-siRNA and NC stable cell lines was determined using qRT-PCR analysis. HULC expression was significantly greater in the NC cell line $(1.043 \pm 0.052)$ compared to the HULC-siRNA cell line $(0.310 \pm 0.038)(t=11.35, P=0.0003)$ (Fig. 1A). This demonstrated that the HULC-siRNA construct effectively reduced HULC expression.

MS data and quality control testing. The MS data are shown in Fig. 1B. The effective spectra were filtered through a database search. In total, 5312 proteins were identified, among which 4630 were quantified (Fig. 1B). To validate the quality of the MS data, we analyzed two quality parameters-peptide mass tolerance and peptide length. Most peptides were within the range of 7-20 amino acids in length, in line with the general rules after trypsin digestion and HCD fragmentation (Fig. 1C). The molecular weight of the proteins negatively correlated with the coverage (Fig. 1D). The mass tolerance of most of the spectra was within $10 \mathrm{ppm}$, which was consistent with the high-precision characteristics of Orbitrap MS (Fig. 1E). The Pearson correlation coefficient between every two replicates was greater than 0.6 , and there was no correlation between different groups, indicating that the obtained protein samples maintained good reproducibility (Fig. 1F).

Identification of proteins exhibiting altered expression in HULC-siRNA cells. We performed LC-MS/MS to identify proteins exhibiting altered expression in HULC-siRNA cells. Comparisons of the quantitative values of protein expression were made between the mean and standard error of the readings of the HULC-siRNA and NC cells. The data were filtered as statistically significant when the $\mathrm{P}$ value was $<0.05$, and a fold change in protein expression $>1.2$ was regarded as up-regulation. Conversely, a fold change in protein expression $<1 / 1.2$ was regarded as down-regulation. A total of 112 up-regulated proteins and 24 down-regulated proteins was detected (Table 1). The top five up-regulated proteins were APOC3, CCDC146, MPZ, CRYAB, and RNF7, and the top five down-regulated proteins were CCDC159, SASH1, ANXA8L1, PLA2G4A, and CYP51A1. A volcano plot shows the $\log 2$ (fold change) as the abscissa, and - $\log 10$ of the P value as the ordinate (Fig. 1G). Our results indicate that HULC knockdown alters the protein profile of GBM cells, which likely contributed to tumor pathogenesis.

Functional classification of identified proteins. To determine the functional characteristics of the identified proteins, three primary annotations were first obtained from the GO analysis: biological process, cellular component, and molecular function. In the GO secondary classification, the differentially expressed proteins were related to some important biological processes, including cells (87.5\%), organelles (75.7\%), and biological regulation processes $(70.6 \%)$. These proteins participate in the composition of multiple cellular components $(75.5 \%)$ and play a pivotal role in molecular binding (94.9\%) and catalytic activity (26.5\%). Moreover, this functional annotation appeared in both up-regulated and down-regulated proteins (Fig. 2A,B). The Fisher's exact test was further applied to the GO functional enrichment analysis of the identified proteins. As shown in Fig. 2C,D, when HULC was silenced, the proteins involved in the formation of the extracellular region were most significantly down-regulated, while proteins forming actin filament bundles were most obviously up-regulated. Demethylase activity and calcium-dependent phospholipid binding were significantly down-regulated, while proteins involved in actin binding were notably up-regulated. Moreover, various lipid metabolism pathways were significantly enriched in biological process (Fig. 2C,D). Directed acyclic graphs (Supplementary Fig. S1) not only intuitively reflect the enrichment differences of each GO classification, but also present the upper and lower hierarchical relationships of GO functions, indicating that GO function enrichment provided a deeper level of classification. For example, actin-dependent ATPase activity was significantly up-regulated at level 10 and calcium-dependent phospholipid binding was enriched in down-regulation at level 6.

KEGG pathway annotation and enrichment. To understand the regulatory network associated with HULC knockdown, KEGG pathway analysis was performed with all differentially expressed proteins. We used the Fisher's exact test to further reveal the significantly enriched proteins in the annotated KEGG pathways. The $\mathrm{P}$ values are presented as - $\log 10$ conversion. Our results indicate that tight junction was the most enriched pathway and that there was a 3.4-fold up-regulation in this pathway following HULC knockdown. The downregulated KEGG pathways were distributed in metabolic pathway, arachidonic acid metabolism, terpenoid backbone biosynthesis, and platelet activation (Fig. 3).

Functional effects of HULC knockdown on U87 cells. To assess the functional effects of HULC silencing on GBM cells, we first analyzed the effect of HULC knockdown on cell proliferation by colony formation assay in U87 cell lines. Proliferating colonies were scored as the 12 days after seeding. Compared to the negative control, the siRNA-mediated knockdown of HULC showed a 3.39-fold decrease in the number of 
A
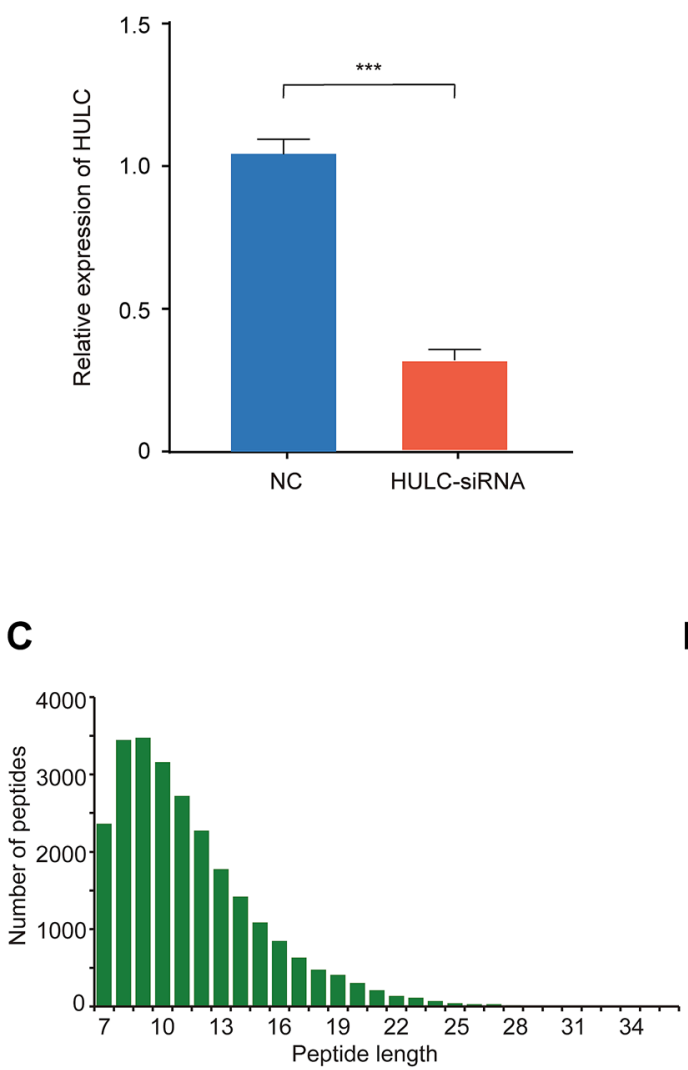

B

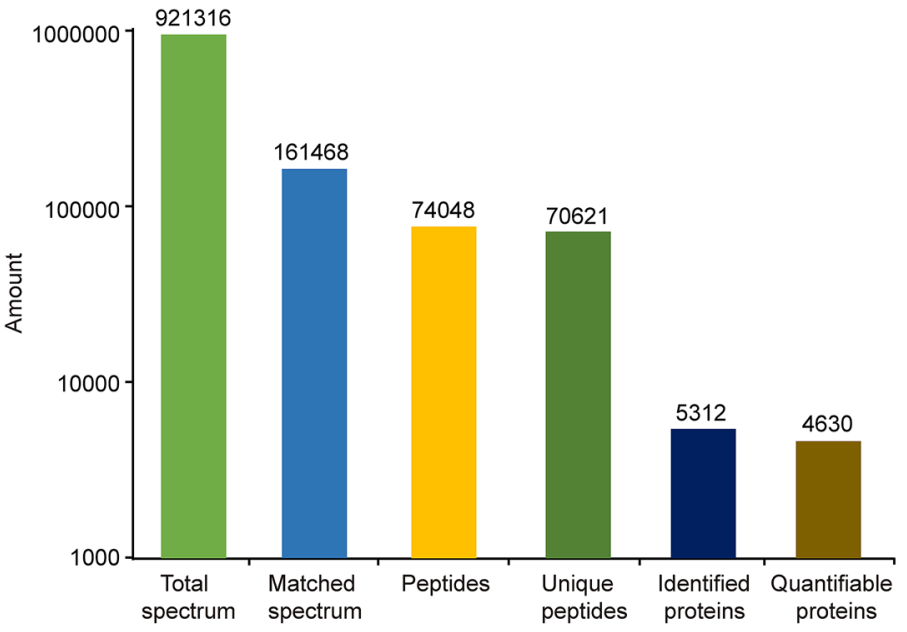

D

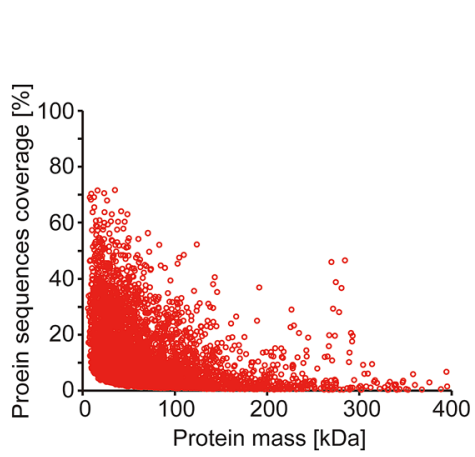

$\mathbf{E}$

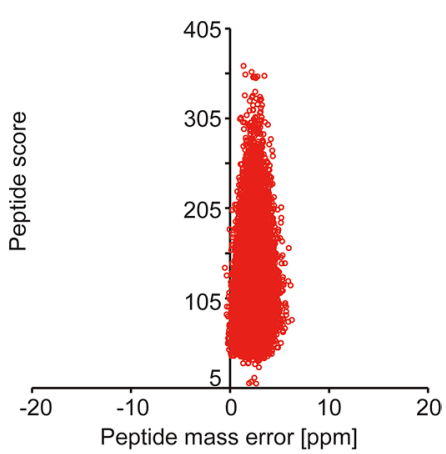

$\mathbf{F}$

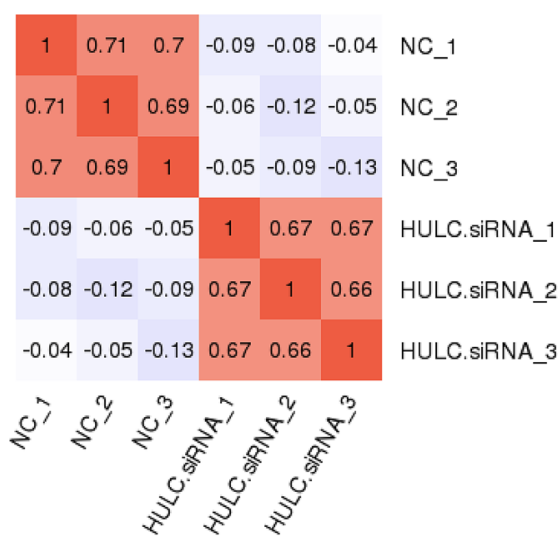

G

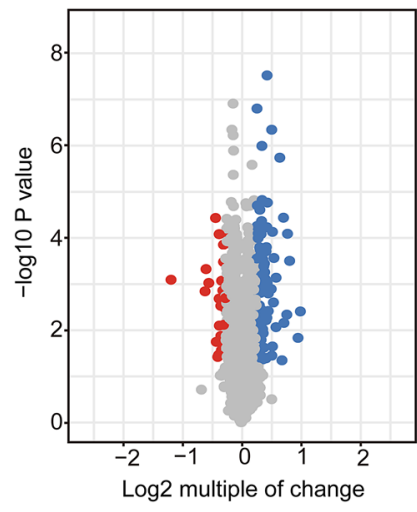

Regulated type

- unchange

- up

- down

Figure 1. Proteins exhibiting altered expression in HULC-siRNA cells. (A) qRT-PCR analysis of the relative expression level of HULC from U87 HULC-siRNA stable cell lines and normal control (NC) $(\mathrm{P}=0.0003)$. (B) Protein identification using MS with spectrum extraction. (C) Peptide distribution in MS analysis. (D) Relationship between proteome coverage and molecular weight. (E) Mass tolerance of most spectra. (F) Pearson correlation coefficient between every two replicates. (G) Volcano plot of differentially expressed proteins quantified using LC-MS/MS.

clusters $(\mathrm{P}=0.0002)$, indicating that cell proliferation was significantly inhibited (Fig. $4 \mathrm{~A})$. We next used the Transwell assay to determine whether HULC knockdown affected cell invasion. We found that HULC knockdown decreased cell invasion capability by 2.45 -fold $(\mathrm{P}=0.0003)$ compared to the negative control (Fig. $4 \mathrm{~B})$. The wound-healing assay showed that cell migration was also suppressed following HULC knockdown. Migration was reduced by 1.84 -fold at $24 \mathrm{~h}(\mathrm{P}=0.0002)$, and 1.62 -fold at $48 \mathrm{~h}(\mathrm{P}=0.0003)$ (Fig. 4C). These data indicate that HULC promotes GBM cell proliferation, invasion, and mobility in vitro. 


\begin{tabular}{|c|c|c|c|c|c|}
\hline Protein accession & Protein description & Gene name & MW [kDa] & siRNA/NC ratio & P value \\
\hline P02656 & Apolipoprotein C-III & APOC3 & 10.852 & 2 & 0.0039812 \\
\hline Q8IYE0 & Coiled-coil domain-containing protein 146 & CCDC146 & 112.81 & 1.946 & 0.0149 \\
\hline P25189 & Myelin protein P0 & MPZ & 27.554 & 1.764 & 0.00031934 \\
\hline P02511 & Alpha-crystallin B chain & CRYAB & 20.159 & 1.721 & 0.00008267 \\
\hline Q9UBF6 & RING-box protein 2 & RNF7 & 12.683 & 1.706 & 0.0046752 \\
\hline Q8TAC9 & Secretory carrier-associated membrane protein 5 & SCAMP5 & 26.104 & 1.65 & 0.0070596 \\
\hline Q01995 & Transgelin & TAGLN & 22.611 & 1.642 & 0.000037074 \\
\hline Q6RFH5 & WD repeat-containing protein 74 & WDR74 & 42.441 & 1.613 & 0.045603 \\
\hline P09493 & Tropomyosin alpha-1 chain & TPM1 & 32.708 & 1.57 & $1.8564 \mathrm{E}-06$ \\
\hline Q8N3V7 & Synaptopodin & SYNPO & 99.462 & 1.506 & 0.00073988 \\
\hline Q6ZN11 & Zinc finger protein 793 & ZNF793 & 46.926 & 1.504 & 0.0087173 \\
\hline P02794 & Ferritin heavy chain & FTH1 & 21.225 & 1.468 & 0.00027678 \\
\hline P04114 & Apolipoprotein B-100 & $\mathrm{APOB}$ & 515.6 & 1.46 & 0.0025445 \\
\hline P30838 & $\begin{array}{l}\text { Aldehyde dehydrogenase, dimeric NADP- } \\
\text { preferring }\end{array}$ & ALDH3A1 & 50.394 & 1.443 & 0.000075171 \\
\hline P27658 & Collagen alpha-1(VIII) chain & COL8A1 & 73.363 & 1.443 & 0.022883 \\
\hline O75882 & Attractin & \begin{tabular}{|l|l|} 
ATRN \\
\end{tabular} & 158.54 & 1.433 & 0.036083 \\
\hline $\mathrm{P} 08670$ & Vimentin & VIM & 53.651 & 1.431 & $4.5998 \mathrm{E}-07$ \\
\hline P21589 & 5'-nucleotidase & NT5E & 63.367 & 1.422 & 0.00130019 \\
\hline Q99715 & Collagen alpha-1(XII) chain & COL12A1 & 333.14 & 1.376 & 0.00162044 \\
\hline $\mathrm{P} 48681$ & Nestin & NES & 177.44 & 1.374 & 0.0038995 \\
\hline Q16643 & Drebrin & DBN1 & 71.428 & 1.361 & $1.74651 \mathrm{E}-05$ \\
\hline Q96C19 & EF-hand domain-containing protein D2 & EFHD2 & 26.697 & 1.361 & 0.00135728 \\
\hline Q08945 & FACT complex subunit SSRP1 & SSRP1 & 81.074 & 1.357 & 0.0009648 \\
\hline Q14315 & Filamin-C & FLNC & 291.02 & 1.355 & $3.0598 \mathrm{E}-08$ \\
\hline Q7Z406 & Myosin-14 & MYH14 & 227.87 & 1.353 & 0.000059659 \\
\hline Q14123 & $\begin{array}{l}\text { Calcium/calmodulin-dependent 3',5'-cyclic } \\
\text { nucleotide phosphodiesterase 1C }\end{array}$ & PDE1C & 80.759 & 1.351 & 0.005461 \\
\hline Q14011 & Cold-inducible RNA-binding protein & CIRBP & 18.648 & 1.344 & 0.000161097 \\
\hline Q9BX67 & Junctional adhesion molecule C & JAM3 & 35.02 & 1.339 & 0.041317 \\
\hline O94875 & Sorbin and SH3 domain-containing protein 2 & SORBS2 & 124.11 & 1.339 & 0.0061629 \\
\hline Q9UKA9 & Polypyrimidine tract-binding protein 2 & PTBP2 & 57.49 & 1.339 & 0.000198578 \\
\hline Q96CT7 & Coiled-coil domain-containing protein 124 & CCDC124 & 25.835 & 1.333 & 0.0060834 \\
\hline Q8WWI5 & Choline transporter-like protein 1 & SLC44A1 & 73.301 & 1.328 & 0.00079616 \\
\hline Q32NB8 & $\begin{array}{l}\text { CDP-diacylglycerol-glycerol-3-phosphate } \\
\text { 3-phosphatidyltransferase, mitochondrial }\end{array}$ & PGS1 & 62.73 & 1.328 & 0.040244 \\
\hline Q8IWT1 & Sodium channel subunit beta-4 & SCN4B & 24.969 & 1.323 & 0.0058581 \\
\hline Q9H936 & Mitochondrial glutamate carrier 1 & SLC25A22 & 34.47 & 1.318 & 0.00056274 \\
\hline Q14978 & Nucleolar and coiled-body phosphoprotein 1 & NOLC1 & 73.602 & 1.314 & 0.0003646 \\
\hline Q92804 & TATA-binding protein-associated factor $2 \mathrm{~N}$ & TAF15 & 61.829 & 1.305 & 0.024261 \\
\hline P07305 & Histone H1.0 & H1F0 & 20.863 & 1.304 & 0.00041633 \\
\hline O15075 & Serine/threonine-protein kinase DCLK1 & DCLK1 & 82.223 & 1.3 & 0.00035882 \\
\hline Q9NQS1 & Cell death regulator Aven & AVEN & 38.506 & 1.295 & 0.0117635 \\
\hline Q7RTV2 & Glutathione S-transferase A5 & GSTA5 & 25.722 & 1.294 & 0.043362 \\
\hline P29972 & Aquaporin-1 & AQP1 & 28.526 & 1.29 & 0.00029842 \\
\hline P49006 & MARCKS-related protein & MARCKSL1 & 19.529 & 1.287 & 0.0096379 \\
\hline P35579 & Myosin-9 & MYH9 & 226.53 & 1.279 & $1.53911 \mathrm{E}-05$ \\
\hline P12814 & Alpha-actinin-1 & ACTN1 & 103.06 & 1.276 & 1.0319E-06 \\
\hline O00159 & Unconventional myosin-Ic & MYO1C & 121.68 & 1.274 & 0.000059025 \\
\hline Q6NZI2 & Caveolae-associated protein 1 & CAVIN1 & 43.476 & 1.271 & 0.000043943 \\
\hline Q5M775 & Cytospin-B & SPECC1 & 118.58 & 1.271 & 0.003664 \\
\hline Q96KR1 & Zinc finger RNA-binding protein & ZFR & 117.01 & 1.269 & 0.00098296 \\
\hline P11532 & Dystrophin & DMD & 426.74 & 1.267 & 0.00143623 \\
\hline O43707 & Alpha-actinin- 4 & ACTN4 & 104.85 & 1.266 & 0.00023728 \\
\hline Q15018 & BRISC complex subunit Abraxas 2 & ABRAXAS2 & 46.9 & 1.266 & 0.043177 \\
\hline Q9NYF8 & Bcl-2-associated transcription factor 1 & BCLAF1 & 106.12 & 1.264 & 0.0164608 \\
\hline P62888 & $60 \mathrm{~S}$ ribosomal protein $\mathrm{L} 30$ & RPL30 & 12.784 & 1.264 & 0.000083727 \\
\hline
\end{tabular}




\begin{tabular}{|c|c|c|c|c|c|}
\hline Protein accession & Protein description & Gene name & MW [kDa] & siRNA/NC ratio & P value \\
\hline $\mathrm{P} 42262$ & Glutamate receptor 2 & GRIA2 & 98.82 & 1.263 & 0.00022379 \\
\hline Q15233 & $\begin{array}{l}\text { Non-POU domain-containing octamer-binding } \\
\text { protein }\end{array}$ & NONO & 54.231 & 1.263 & 0.000075548 \\
\hline P00966 & Argininosuccinate synthase & ASS1 & 46.53 & 1.263 & 0.0076647 \\
\hline Q9UHB6 & LIM domain and actin-binding protein 1 & LIMA1 & 85.225 & 1.259 & 0.0050829 \\
\hline O43281 & Embryonal Fyn-associated substrate & EFS & 58.815 & 1.258 & 0.042856 \\
\hline Q9BVA1 & Tubulin beta-2B chain & TUBB2B & 49.953 & 1.258 & 0.0052591 \\
\hline Q15052 & Rho guanine nucleotide exchange factor 6 & ARHGEF6 & 87.498 & 1.256 & 0.00157834 \\
\hline P53999 & $\begin{array}{l}\text { Activated RNA polymerase II transcriptional } \\
\text { coactivator p15 }\end{array}$ & SUB1 & 14.395 & 1.255 & 0.000184969 \\
\hline Q9H2L5 & Ras association domain-containing protein 4 & RASSF4 & 36.748 & 1.253 & 0.00019808 \\
\hline Q9Y4J8 & Dystrobrevin alpha & DTNA & 83.9 & 1.25 & 0.043597 \\
\hline Q8IWA4 & Mitofusin-1 & MFN1 & 84.159 & 1.25 & 0.0151353 \\
\hline Q6GYQ0 & Ral GTPase-activating protein subunit alpha-1 & RALGAPA1 & 229.83 & 1.248 & 0.0142205 \\
\hline Q9Y3E1 & $\begin{array}{l}\text { Hepatoma-derived growth factor-related protein } \\
3\end{array}$ & HDGFL3 & 22.619 & 1.248 & 0.040119 \\
\hline Q9Y2D5 & A-kinase anchor protein 2 & AKAP2 & 94.659 & 1.245 & 0.0149596 \\
\hline Q13557 & $\begin{array}{l}\text { Calcium/calmodulin-dependent protein kinase } \\
\text { type II subunit delta }\end{array}$ & CAMK2D & 56.369 & 1.245 & 0.000024929 \\
\hline Q6DN90 & IQ motif and SEC7 domain-containing protein 1 & IQSEC1 & 108.31 & 1.244 & 0.000162383 \\
\hline P39019 & 40S ribosomal protein S19 & RPS19 & 16.06 & 1.242 & 0.000164125 \\
\hline Q01130 & Serine/arginine-rich splicing factor 2 & SRSF2 & 25.476 & 1.242 & 0.033157 \\
\hline Q9UPQ7 & E3 ubiquitin-protein ligase PDZRN3 & PDZRN3 & 119.6 & 1.239 & 0.000083308 \\
\hline Q96T51 & RUN and FYVE domain-containing protein 1 & RUFY1 & 79.817 & 1.239 & 0.00116479 \\
\hline P08138 & $\begin{array}{l}\text { Tumor necrosis factor receptor superfamily } \\
\text { member } 16\end{array}$ & NGFR & 45.183 & 1.238 & 0.0092784 \\
\hline Q05682 & Caldesmon & CALD1 & 93.23 & 1.238 & 0.00008386 \\
\hline Q9P2K5 & Myelin expression factor 2 & MYEF2 & 64.121 & 1.238 & 0.0029401 \\
\hline Q92556 & Engulfment and cell motility protein 1 & ELMO1 & 83.829 & 1.238 & 0.0050598 \\
\hline Q9Y6R0 & Numb-like protein & NUMBL & 64.891 & 1.235 & 0.00064428 \\
\hline Q6WCQ1 & Myosin phosphatase Rho-interacting protein & MPRIP & 116.53 & 1.235 & 0.0161641 \\
\hline Q9BQ89 & Protein FAM110A & FAM110A & 31.27 & 1.233 & 0.03976 \\
\hline Q14938 & Nuclear factor $1 \mathrm{X}$-type & NFIX & 55.098 & 1.229 & 0.0089995 \\
\hline O75914 & Serine/threonine-protein kinase PAK 3 & PAK3 & 62.309 & 1.225 & 0.0048774 \\
\hline $\mathrm{P} 16403$ & Histone H1.2 & HIST1H1C & 21.364 & 1.224 & 0.000096264 \\
\hline Q13509 & Tubulin beta- 3 chain & TUBB3 & 50.432 & 1.222 & 0.030999 \\
\hline Q6ICG6 & Uncharacterized protein KIAA0930 & KIAA0930 & 45.794 & 1.221 & 0.0044973 \\
\hline Q9Y3Y2 & Chromatin target of PRMT1 protein & CHTOP & 26.396 & 1.221 & 0.000080975 \\
\hline P50579 & Methionine aminopeptidase 2 & METAP2 & 52.891 & 1.221 & 0.000102665 \\
\hline Q9P2X3 & Protein IMPACT & IMPACT & 36.476 & 1.22 & 0.00085821 \\
\hline Q9Y2E5 & Epididymis-specific alpha-mannosidase & MAN2B2 & 113.98 & 1.22 & 0.00092274 \\
\hline Q96L93 & Kinesin-like protein KIF16B & KIF16B & 152.01 & 1.22 & 0.035896 \\
\hline P09471 & $\begin{array}{l}\text { Guanine nucleotide-binding protein G(o) subunit } \\
\text { alpha }\end{array}$ & GNAO1 & 40.05 & 1.217 & 0.000060744 \\
\hline Q8NCN5 & $\begin{array}{l}\text { Pyruvate dehydrogenase phosphatase regulatory } \\
\text { subunit, mitochondrial }\end{array}$ & PDPR & 99.363 & 1.215 & 0.038562 \\
\hline O60315 & Zinc finger E-box-binding homeobox 2 & ZEB2 & 136.45 & 1.215 & 0.00147829 \\
\hline P57723 & Poly(rC)-binding protein 4 & PCBP4 & 41.481 & 1.215 & 0.0119597 \\
\hline O15061 & Synemin & SYNM & 172.77 & 1.212 & 0.00047684 \\
\hline P19338 & Nucleolin & NCL & 76.613 & 1.212 & 0.000095076 \\
\hline Q8N684 & $\begin{array}{l}\text { Cleavage and polyadenylation specificity factor } \\
\text { subunit } 7\end{array}$ & CPSF7 & 52.049 & 1.209 & 0.00056162 \\
\hline Q14195 & Dihydropyrimidinase-related protein 3 & DPYSL3 & 61.963 & 1.209 & 0.00055675 \\
\hline P45973 & Chromobox protein homolog 5 & CBX5 & 22.225 & 1.209 & 0.000020132 \\
\hline Q9UBS8 & E3 ubiquitin-protein ligase RNF14 & RNF14 & 53.837 & 1.209 & 0.00137693 \\
\hline P23246 & Splicing factor, proline- and glutamine-rich & SFPQ & 76.149 & 1.209 & 0.0037786 \\
\hline P62244 & $40 \mathrm{~S}$ ribosomal protein $\mathrm{S} 15 \mathrm{a}$ & RPS15A & 14.839 & 1.208 & 0.0093783 \\
\hline P17480 & Nucleolar transcription factor 1 & UBTF & 89.405 & 1.208 & 0.000055962 \\
\hline P54792 & $\begin{array}{l}\text { Putative segment polarity protein dishevelled } \\
\text { homolog DVL1P1 }\end{array}$ & DVL1P1 & 73.253 & 1.206 & 0.0079626 \\
\hline
\end{tabular}




\begin{tabular}{|c|c|c|c|c|c|}
\hline Protein accession & Protein description & Gene name & MW [kDa] & siRNA/NC ratio & P value \\
\hline Q9Y5J5 & $\begin{array}{l}\text { Pleckstrin homology-like domain family A } \\
\text { member } 3\end{array}$ & PHLDA3 & 13.891 & 1.206 & 0.0066224 \\
\hline O95319 & CUGBP Elav-like family member 2 & CELF2 & 54.284 & 1.205 & 0.0039437 \\
\hline P22626 & Heterogeneous nuclear ribonucleoproteins A2/B1 & HNRNPA2B1 & 37.429 & 1.205 & 1.5989E-07 \\
\hline Q86V81 & THO complex subunit 4 & ALYREF & 26.888 & 1.205 & 0.0036446 \\
\hline Q8WV24 & $\begin{array}{l}\text { Pleckstrin homology-like domain family A } \\
\text { member } 1\end{array}$ & PHLDA1 & 45.016 & 1.205 & 0.00028372 \\
\hline Q5VIR6 & $\begin{array}{l}\text { Vacuolar protein sorting-associated protein } 53 \\
\text { homolog }\end{array}$ & VPS53 & 79.652 & 1.203 & 0.0177626 \\
\hline Q9Y2B9 & cAMP-dependent protein kinase inhibitor gamma & PKIG & 7.9104 & 1.202 & 0.025196 \\
\hline P61586 & Transforming protein RhoA & RHOA & 21.768 & 0.833 & 0.0020439 \\
\hline P06703 & Protein S100-A6 & S100A6 & 10.18 & 0.829 & 0.00169719 \\
\hline Q6NYC1 & $\begin{array}{l}\text { Bifunctional arginine demethylase and lysyl- } \\
\text { hydroxylaseJMJD6 }\end{array}$ & JMJD6 & 46.461 & 0.827 & 0.0197959 \\
\hline Q969H8 & Myeloid-derived growth factor & MYDGF & 18.795 & 0.824 & 0.000081223 \\
\hline P18827 & Syndecan-1 & SDC1 & 32.461 & 0.82 & 0.0032242 \\
\hline Q9H900 & Protein zwilch homolog & ZWILCH & 67.213 & 0.817 & 0.007761 \\
\hline P53602 & Diphosphomevalonate decarboxylase & MVD & 43.404 & 0.815 & 0.00033664 \\
\hline P48735 & Isocitrate dehydrogenase [NADP], mitochondrial & IDH2 & 50.909 & 0.814 & 0.000142651 \\
\hline Q9BWD1 & Acetyl-CoA acetyltransferase, cytosolic & ACAT2 & 41.35 & 0.808 & 0.00140305 \\
\hline Q9ULF5 & Zinc transporter ZIP10 & SLC39A10 & 94.131 & 0.797 & 0.00086387 \\
\hline Q9NZA1 & Chloride intracellular channel protein 5 & CLIC5 & 46.502 & 0.796 & 0.027481 \\
\hline Q9Y5U8 & Mitochondrial pyruvate carrier 1 & MPC1 & 12.347 & 0.79 & 0.0135035 \\
\hline P23219 & Prostaglandin G/H synthase 1 & PTGS1 & 68.686 & 0.789 & 0.0030041 \\
\hline O60218 & Aldo-keto reductase family 1 member B10 & AKR1B10 & 36.019 & 0.776 & 0.0080781 \\
\hline $\mathrm{P} 13521$ & Secretogranin-2 & SCG2 & 70.94 & 0.774 & 0.0021022 \\
\hline P07451 & Carbonic anhydrase 3 & CA3 & 29.557 & 0.774 & 0.000084276 \\
\hline P05109 & Protein S100-A8 & S100A8 & 10.834 & 0.769 & 0.034876 \\
\hline Q12872 & $\begin{array}{l}\text { Splicing factor, suppressor of white-apricot } \\
\text { homolog }\end{array}$ & SFSWAP & 104.82 & 0.762 & 0.038515 \\
\hline Q6ZMG9 & Ceramide synthase 6 & CERS6 & 44.889 & 0.749 & 0.0181562 \\
\hline Q16850 & Lanosterol 14-alpha demethylase & CYP51A1 & 56.805 & 0.742 & 0.000037594 \\
\hline $\mathrm{P} 47712$ & Cytosolic phospholipase A2 & PLA2G4A & 85.238 & 0.686 & 0.00096189 \\
\hline Q5VT79 & Annexin A8-like protein 1 & ANXA8L1 & 36.879 & 0.664 & 0.00048202 \\
\hline O94885 & SAM and SH3 domain-containing protein 1 & SASH1 & 136.65 & 0.657 & 0.00145894 \\
\hline P0C7I6 & Coiled-coil domain-containing protein 159 & CCDC159 & 33.695 & 0.441 & 0.00081975 \\
\hline
\end{tabular}

Table 1. An overview of 136 differentially expressed proteins identified in GBM cell lines. MW molecular weight, FACT facilitates chromatin transactions, SSRP structure specific recognition protein, DCLK double cortin like kinase, $P R M T$ protein arginine methyltransferase.

HULC regulates PLA2G4A protein expression. To identify key proteins regulated by HULC, we analyzed the common proteins of several significantly different signaling pathways (arachidonic acid metabolism, platelet activation, etc.). As a result, we found that the protein encoded by PLA2G4A plays a pivotal role in these pathways. Therefore, we used Western blot analysis to verify differences in PLA2G4A protein expression. Our results showed that knockdown of HULC significantly reduced the protein abundance of PLA2G4A (Fig. 4D).

\section{Discussion}

GBM is a grade IV glioma and is the most aggressive malignant type of brain tumor. Increasing evidence demonstrates that many lncRNAs play various roles in a series of biological processes associated with the occurrence and development of GBM. For example, high expression of PVT1 in the nucleus can accelerate glioma cell proliferation, invasion, and aerobic glycolysis by inhibiting the expression of miR-140-5 $\mathrm{p}^{17}$. GAS5-AS1 is another lncRNA expressed in glioma tissues. One study showed that GAS5-AS1 binded to miR-106b-5p to promote expression of downstream genes that play a role in inhibiting cell proliferation, migration, and invasion of glioma cells ${ }^{18}$. Emerging studies have invested the mechanisms by which lncRNAs influence other tumor behavior ${ }^{19,20}$. Much of these efforts have been focused on identifying highly specific and sensitive biomarkers to promote early diagnosis, predict prognosis, and provide potential therapeutic targets for different cancers.

The lncRNA HULC has been shown to be highly expressed in GBM cells compared to normal cells, as well as to promote the proliferation of GBM cells in vitro ${ }^{11}$. Zhu et al. found that silencing HULC inhibited glioma angiogenesis through the ESM-1-mediated PI3K/AKT/mTOR signaling pathway, resulting in GBM growth 
A

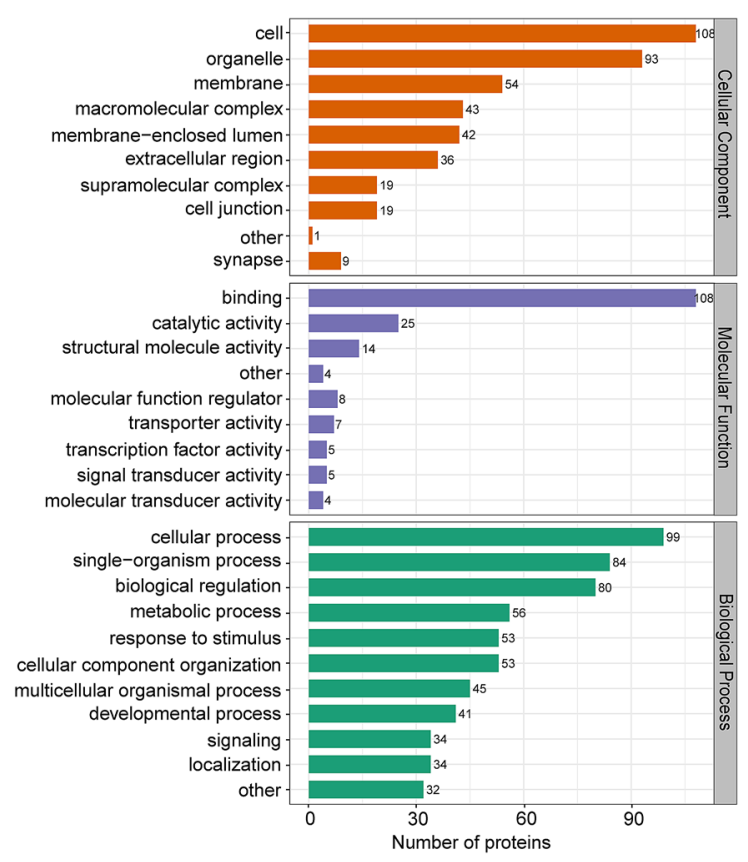

C

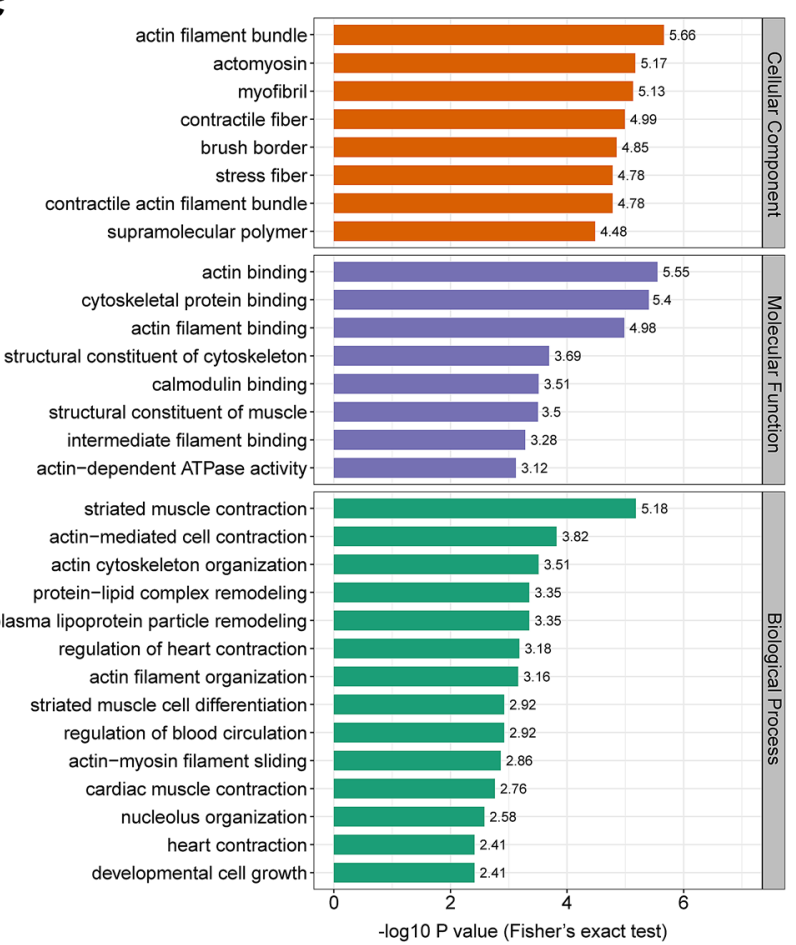

B

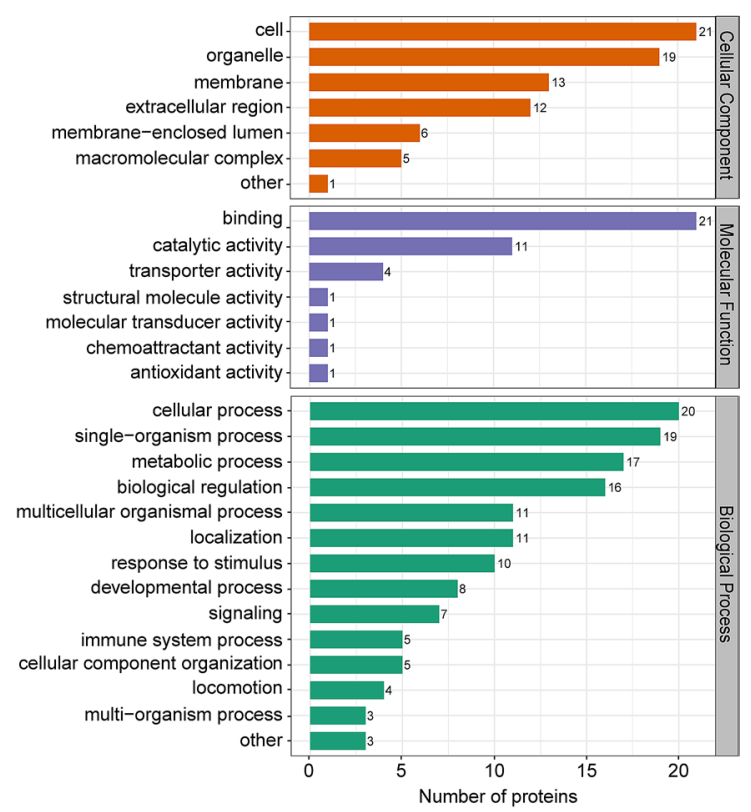

D

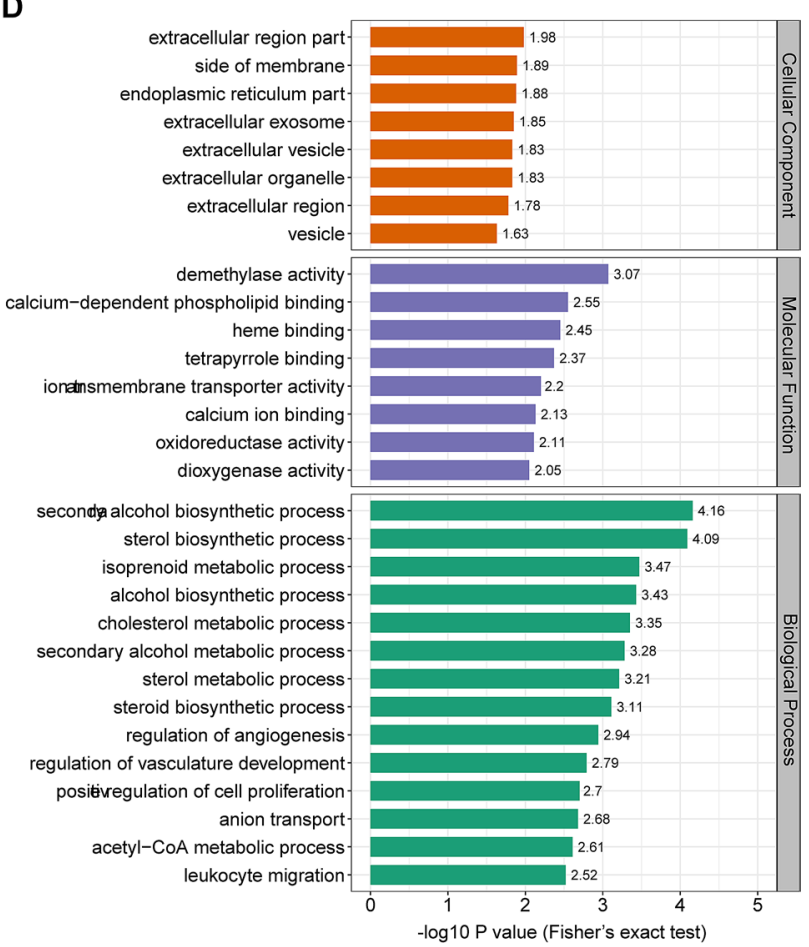

Figure 2. GO annotation and enrichment. (A) Selected proteins with a significant increase in abundance in cellular component, molecular function, and biological process, respectively. (B) Selected proteins with a significant decrease in abundance under the above classification. (C) GO enrichment analysis of the up-regulated proteins in biological process, cellular component, and molecular function. (D) GO enrichment analysis of the down-regulated proteins under the above classification.

suppression ${ }^{12}$. However, the molecular mechanisms responsible for HULC's regulation in GBM tumorigenesis have only begun to be scrutinized. Our study provides insight into this mechanism by identifying the potential targets of HULC in glioma cells.

Proteomics research has gained much attention in tumor biology studies. Farhadul et al. analyzed differences in the total proteome between esophageal squamous cell carcinoma and non-tumor cells using label-free shotgun proteomics combined with $\mathrm{MS}^{13}$. Zhao et al. screened tumor-specific antigens for high-grade serous ovarian cancer with MS, and found potential targets for ovarian cancer immunotherapy ${ }^{14}$. In this study, we obtained 

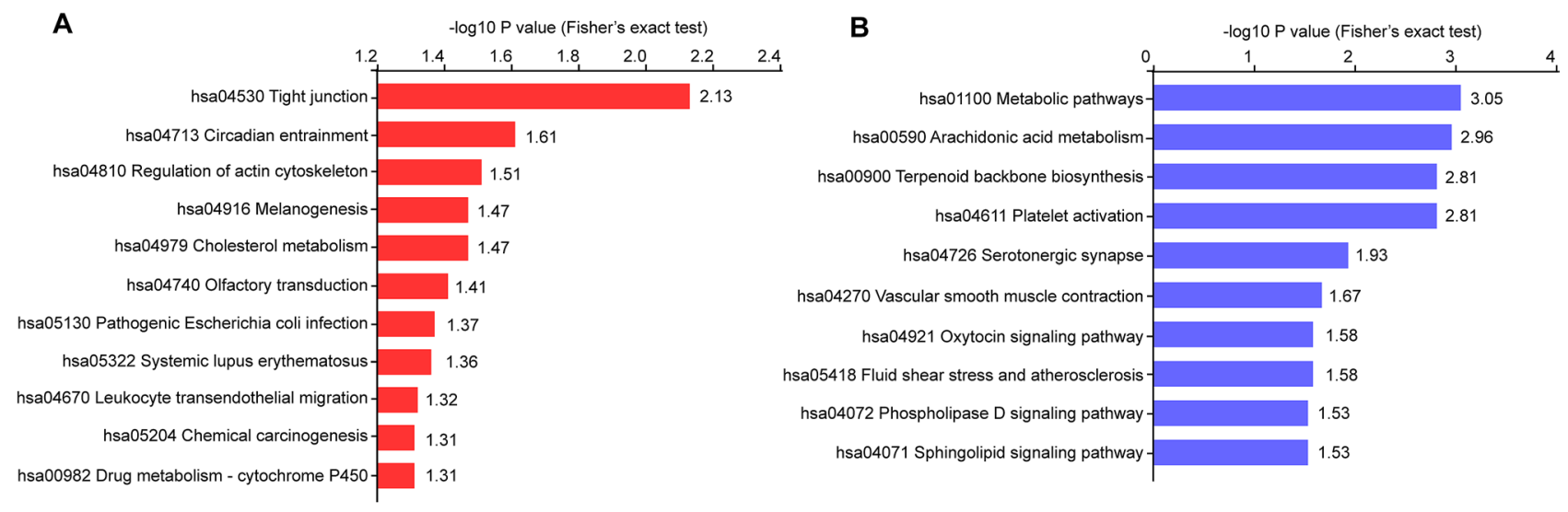

Figure 3. KEGG pathway enrichment in dysregulated proteins. (A) KEGG pathway enrichment of up-regulated proteins was performed using the Fisher's exact test, which indicates that tight junction was the most enriched pathway. (B) Plot exhibiting 10 down-regulated KEGG pathways with significant enrichment.

A
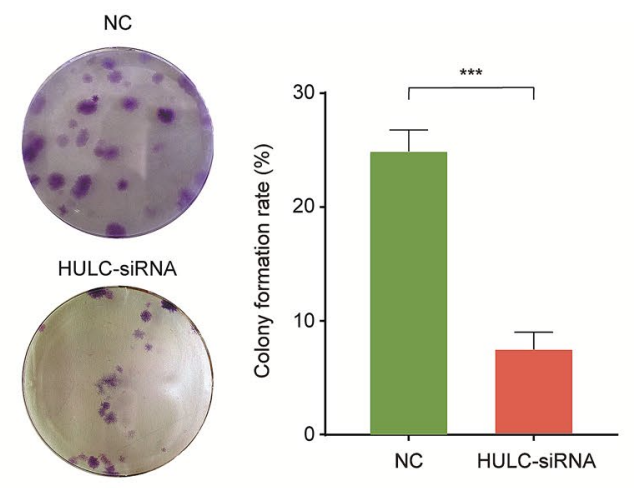

C

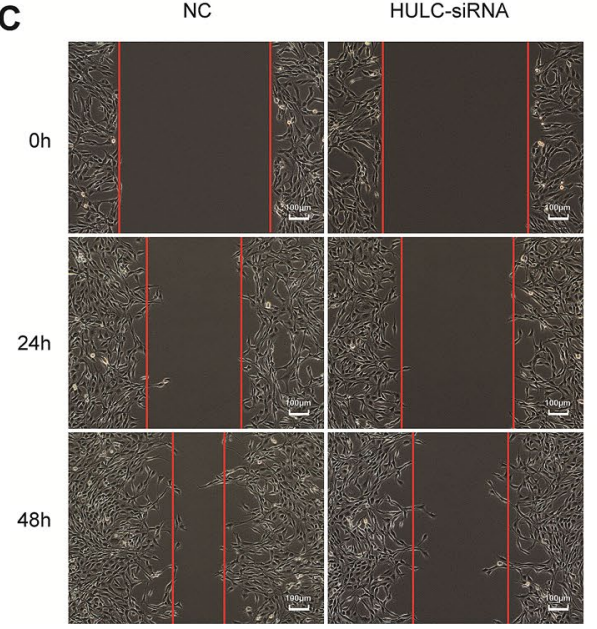

B
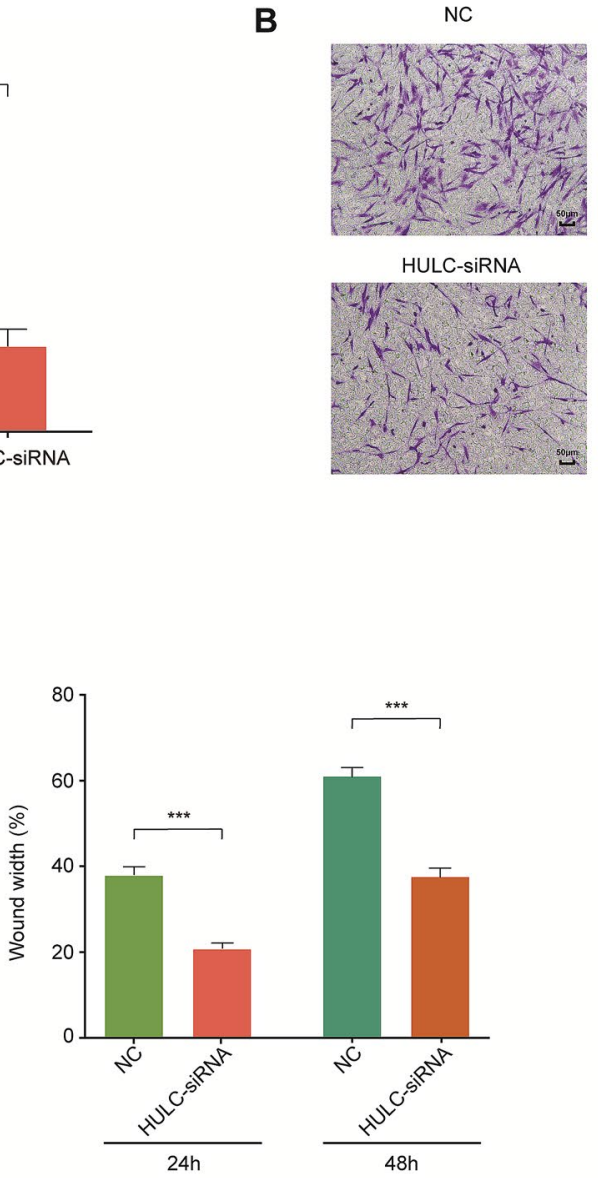

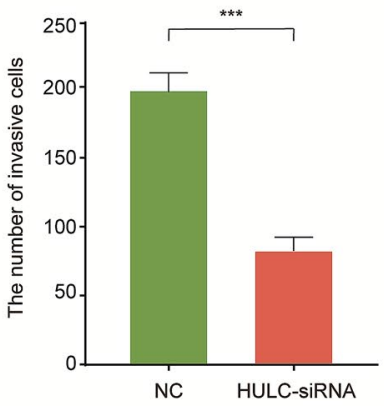

D
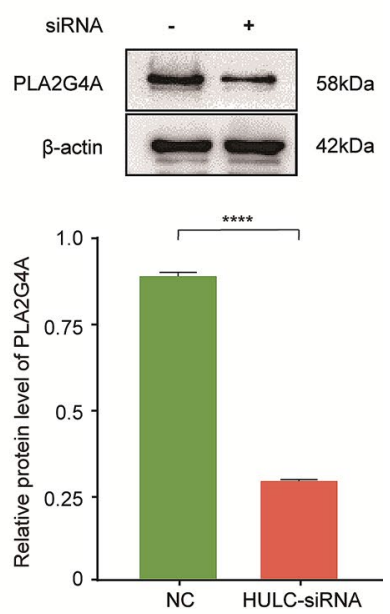

Figure 4. The effects of HULC inhibition to U87 cells. (A) Number of cell clusters reduced in response to HULC silencing $(\mathrm{P}=0.0002)$. (B) HULC knockdown inhibited cell invasion determined using the Transwell assay $(\mathrm{P}=0.0003)$. (C) Wound-healing assay was performed to elucidate cell migration after HULC knockdown (24 h, P=0.0002; $48 \mathrm{~h}, \mathrm{P}=0.0003$ ). (D) Protein abundance of PLA2G4A was decreased after HULC knockdown as determined by Western blot analysis $(\mathrm{P}<0.0001) .{ }^{*} \mathrm{P}<0.05,{ }^{*} \mathrm{P}<0.01,{ }^{* * *} \mathrm{P}<0.001,{ }^{* * * *} \mathrm{P}<0.0001$.

the proteome of HULC deficient GBM cells using TMT labeling. Through HPLC fractionation technology and LC-MS/MS analysis, we have new insights into some promising GBM biomarkers.

Among the differentially expressed proteins, we selected the top 5 up-regulated and 5 down-regulated proteins to further analyze. Based on a search of the PubMed database, none of these 10 proteins was previously reported to be related to HULC. Only two of the proteins, CRYAB and SASH1, have been studied in glioma ${ }^{21,22}$. 
Kore et al. demonstrated that the expression level of CRYAB was elevated in U373 glioma cells ${ }^{21}$. Methylation of SASH1 gene has been shown to inhibit cell adhesion and promote migration of astrocytes ${ }^{22}$. The remaining 8 proteins have not been previously reported to have any association with glioma. Although we did not further analyze these 8 proteins in the current study, we believe future in-depth analysis of these proteins will be helpful to better understand the underlying molecular mechanisms in GBM.

However, the GO findings were unexpected in that we identified some up-regulated proteins in cell activity, such as actin filament bundles and actin binding after HULC knockdown, that indicate that HULC suppression can promote tumor migration and invasion, which contradicts our functional results. We speculate that this discrepancy correlates with the complex characteristics of glial cells. In addition to participating in the formation of actin frameworks, glial cells can contract and phagocytose cell fragments, as well as repair and replenish neurons. We also acknowledge that there are likely differences between the MS data and actual verification results ${ }^{23}$. The biosynthesis pathway of the terpenoid backbone was significantly down-regulated, indicating that HULC knockdown exhibited a suppressive effect on cell proliferation. In addition, the strong down-regulation of the platelet activation pathway suggested that HULC was associated with GBM complications, such as thrombosis, to a certain extent ${ }^{24}$. DNA methylation is known to be an early event of tumorigenesis. MGMT (O6-methylguanine-DNA methyltransferase) is a DNA repair enzyme. It was reported that the methylation of the MGMT gene promoter is associated with glioma prognosis and recurrence ${ }^{25}$. Our proteomics analysis demonstrated that demethylase activity was decreased after HULC knockdown. Previous studies have also illustrated that demethylation behavior could promote tumorigenesis and progression ${ }^{26,27}$. Thus, the methylation or demethylation of HULC's target gene should be investigated in future studies.

We found that the PLA2G4A encoded protein appeared in several notable KEGG pathways. Therefore, we hypothesized that PLA2G4A might be a potential downstream target of HULC. PLA2G4A is the most abundant subtype in the family of phospholipase A2. Phospholipase hydrolyzes membrane phospholipids and releases arachidonic acid, which is further involved in many pathophysiological processes, including inflammation, signal transmission, and cell growth ${ }^{28}$. Although one study showed that reducing PLA2G4A expression could promote the migration and invasion of esophageal squamous cell carcinoma ${ }^{29}$, others proposed that PLA2G4A was an oncogen $e^{30-32}$. For example, PLA2G4A has been shown to facilitate the metastasis of osteosarcoma by promoting epithelial-mesenchymal transition (EMT) ${ }^{32}$. Our proteomics data supported PLA2G4A's role as an oncogene. Our independent Western blot assay also confirmed that the HULC knockdown significantly reduced PLA2G4A protein expression, suggesting that PLA2G4A might be a key protein that was regulated by HULC in GBM. Our enrichment analysis showed that PLA2G4A was involved in many important processes, including positive regulation of cell proliferation, calcium-dependent phospholipid binding, and the arachidonic acid metabolism pathway. Since the concept of tumor-promoting inflammation was proposed in 2011, tumor-associated inflammation has been considered a trigger point for cancer progression ${ }^{33}$. We hypothesize that PLA2G4A may also play an important role in the formation of tumor-related inflammation. Thus, targeting PLA2G4A might provide a promising therapy to GBM. Moreover, Tsuji S, et al. put forward that temozolomide might affect cPLA2 ${ }^{34}$, which inspired us that targeting PLA2G4A might reverse temozolomide resistance.

This study has some limitations that should be noted. As we were limited to studying HULC with one cell line, and the validation of the LC-MS/MS data was performed only with one down-regulated protein. It remains for future experiments to further confirm the proteomic analysis results and to determine whether additional targets of HULC can be identified.

\section{Conclusions}

In the era of big data, it is important to identify molecules that can guide the direction of disease research through in-depth analysis of gene and protein profiles. Our study indicates that HULC significantly changes the proteomic characteristics of U87 cell line, and that PLA2G4A is negatively regulated by HULC knockdown in GBM cells. This study provides a new perspective on the pathogenesis of GBM, and also provides a potential target for GBM treatment.

\section{Methods}

Cell culture and transfection. The human GBM glioma cell line, U87, was obtained from China Center for Type Culture Collection (Wuhan, China) and maintained in Dulbecco's modified eagle's medium (DMEM) (BD, USA) supplemented with $10 \%$ fetal bovine serum (FBS) (BD, USA). The cells were grown at $37^{\circ} \mathrm{C}$ in a $5 \%$ $\mathrm{CO}_{2}$ atmosphere.

To generate lentivirus stable cell lines, cells were digested, resuspended, and plated in six-well dishes (Nest, China) at a density of approximately $10 \times 10^{5}$ cells per well, and then cultured under the same conditions for $24 \mathrm{~h}$. The lentiviral vectors (LV3-shNC and LV3-shHULC) and lentiviral packaging were purchased from GenePharma (Shanghai, China). The overall transfection procedure was in accordance with the recommendations of the manufacturer. A $200 \mu \mathrm{l}$ lentivirus stock solution was diluted 5 times with DMEM containing 10\% FBS according to the manufacture's protocol. Infection enhancer polybrene (Sigma, USA) was added to a final concentration of $5 \mu \mathrm{g} / \mathrm{ml}$. Stably-transfected cells were selected by puromycin $(1 \mu \mathrm{g} / \mathrm{ml}$, Sangon, Shanghai, China) and the green fluorescent protein (GFP) was observed under a fluorescence microscope (Olympus, Japan). After a $96 \mathrm{~h}$ in culture, the cells were harvested and stored at $-80^{\circ} \mathrm{C}$ for subsequent experiments. Thus, two stable siRNA expressing cell lines were constructed, including HULC-siRNA and the negative control (NC). The sequence of shRNA targeting HULC was 5'-GAACTCTGATCGTGGACATTT-3'.

Quantitative Real-Time Polymerase Chain Reaction (qRT-PCR). In a week, RNA was extracted from two samples using a total RNA extraction kit (QIAGEN, Germany). cDNA was synthesized according 


\begin{tabular}{|l|l|}
\hline Parameter & Value \\
\hline Range & $350-1550 \mathrm{~m} / \mathrm{z}$ \\
\hline Primary MS & $100 \mathrm{~m} / \mathrm{z}$ (fixed starting point) \\
\hline MS/MS & \multicolumn{2}{|l}{} \\
\hline Resolution & 60,000 \\
\hline Primary MS & 15,000 \\
\hline MS/MS & 50,000 \\
\hline Automatic gain control & 50,000 ions/s \\
\hline Signal threshold & $70 \mathrm{~ms}$ \\
\hline Maximum injection time & $30 \mathrm{~s}$ \\
\hline Dynamically exclude time &
\end{tabular}

Table 2. MS scan parameters.

to the protocol of the high-throughput cDNA reverse transcription kit (Thermo Fisher Scientific, USA). PCR was carried out under 40 cycles of $95^{\circ} \mathrm{C}$ for $12 \mathrm{~s}, 55^{\circ} \mathrm{C}$ for $30 \mathrm{~s}$, and $72{ }^{\circ} \mathrm{C}$ for $1 \mathrm{~min}$. The relative expression levels of the target genes were obtained using two variations of the $2^{-\Delta \Delta \mathrm{Ct}}$ method. Each sample type was run in triplicate. Data were analyzed using the two-tailed $t$ test. ACTB was used as the reference gene. The primers were as follows: HULC forward primer for the upstream sequence: 5'-TCAACCTCCAGAACTGTGATCC-3', HULC reverse primer for the downstream sequence: 5'-TGCTTGATGCTTTGGTCTGTT-3'; ACTB forward primer for the upstream sequence: 5'-CGTGGACATCCGCAAAGA-3', ACTB reverse primer for the downstream sequence: 5'-GAAGGTGGACAGCGAGGC-3'.

Protein extraction. Cells were submitted to protein extraction after 3 months post transfection. Samples were sonicated 4 times on ice with a high intensity ultrasonic processor (Scientz, China) at $30 \%$ amplitude for no more than 7 consecutive seconds in diluted lysis buffer [ $8 \mathrm{M}$ urea (Sigma, UAS), $1 \%$ protease inhibitor (Calbiochem, Germany), and $2 \mathrm{mM}$ EDTA (Sigma, USA)]. The supernatant was collected by centrifugation at $12,000 \times g$ at $4{ }^{\circ} \mathrm{C}$ for $10 \mathrm{~min}$. The protein concentration was determined using a BCA kit (Beyotime, China) according to the manufacturer's instructions.

Trypsin digestion. Dithiothreitol (DTT) (Sigma, USA) ( $5 \mathrm{nM}$ ) was used for every $0.3 \mathrm{mg}$ protein reduction for $30 \mathrm{~min}$ at $56^{\circ} \mathrm{C}$. Iodoacetamide (Sigma, USA) was added to a final concentration of $11 \mathrm{nM}$, and the mixture was incubated at room temperature for $15 \mathrm{~min}$ in the dark. Trypsin (Promega, USA) was added using a trypsin/ protein ratio of 1:50 for the first digestion overnight at $37^{\circ} \mathrm{C}$ and trypsin/protein ratio of 1:100 for a second digestion for $4 \mathrm{~h}$.

Tandem mass tags (TMT) labeling. The digested peptides were desalted using a Strata X C18 SPE column (Phenomenex) and freeze-dried in the vacuum environment. Peptides were reconstituted in $0.5 \mathrm{M} \mathrm{NH}_{4} \mathrm{HCO}_{3}$ (Sigma, USA) and labeled using a TMT kit (Thermo Fisher Scientific, USA) according to the manufacturer's protocol.

High performance liquid chromatography (HPLC) fractionation. The Agilent 300 Extend C18 reversed-phase column ( $5 \mu \mathrm{m}$ particles, $4.6 \mathrm{~mm}$ inner diameter, $250 \mathrm{~mm}$ length) was used to fractionate $0.2 \mathrm{mg}$ peptides into 60 fractions with a gradient of $8 \%$ to $32 \%$ acetonitrile (Fisher Chemical, USA) under the condition of $\mathrm{pH} 9$ over $60 \mathrm{~min}$. The peptides were then combined into 9 components and freeze-dried by vacuum centrifuging.

LC-MS/MS analysis. Two types of liquid chromatography mobile phases were first prepared. Phase A: an aqueous solution containing $0.1 \%$ formic acid (Fluka, USA) and $2 \%$ acetonitrile; Phase B: an aqueous solution containing $0.1 \%$ formic acid and $90 \%$ acetonitrile. Peptides were dissolved in phase A and separated using the EASY-nLC 1000 UPLC system (Thermo Fisher Scientific, USA) at a constant flow rate of $400 \mathrm{~nL} / \mathrm{min}$. The separation gradient was set to increase from 8 to $16 \%$ in phase B within $30 \mathrm{~min}$, then increased to $30 \%$ within $25 \mathrm{~min}$ and $80 \%$ within $2 \mathrm{~min}$, which was maintained for $3 \mathrm{~min}$. The peptides were injected into the nanospray ionization source for ionization at a voltage of $2.0 \mathrm{kV}$. The precursor ions and the secondary fragments of the peptides were detected and analyzed using the Orbitrap Fusion Lumos high-resolution mass spectrometer (Thermo Fisher Scientific, USA). According to the data dependent acquisition (DDA) mode, the precursor ions with top 20 signal intensities after primary scan were fragmented with $32 \%$ fragmentation energy in the HCD collision cell. The secondary MS/MS scan then followed. The MS scan parameters are shown in Table 2.

Bioinformatics analysis. The secondary MS data obtained was retrieved using the Maxquant database (v.1.5.2.8, http://www.maxquant.org/), and the relevant parameters are shown in Table 3.

The quantitative values of each sample in three replicates were obtained. The Pearson correlation coefficient was calculated between two pairs to assess whether the results of replicate samples were statistically consistent. 


\begin{tabular}{|l|l|}
\hline Parameter & Value \\
\hline Protein database & SwissProt Human (20317 sequences) \\
\hline Cleavage enzyme & Trypsin/P \\
\hline Missing cleavages & 2 \\
\hline Minimum length of peptide & 7 amino acid residues \\
\hline Maximum modifications of peptide & 5 \\
\hline Mass tolerance for precursor ions & \multicolumn{2}{|l|}{} \\
\hline First search & 20 ppm20 ppm \\
\hline Main search & 5 ppm \\
\hline Mass tolerance for fragment ions & 0.02 Da \\
\hline Fixed modification & Carbamidomethyl on Cys \\
\hline Variable modification & oxidation on Met, N-terminal acetylation \\
\hline Quantitative method & TMT-6plex \\
\hline FDR for protein identification & $1 \%$ \\
\hline FDR for PSM identification & $1 \%$ \\
\hline
\end{tabular}

Table 3. Relevant parameters for Maxquant database searching.

Using the average of the three quantitative values, we calculated the ratio of the average between the two samples. Fold change was defined as the ratio of the average values of HULC-siRNA to NC. The relative quantitative value of each sample was $\log 2$ transformed to conform the data for normal distribution. Quantified data between the two groups were evaluated using a two-tailed test. Differentially expressed proteins were filtrated based on the following criteria: fold change was equal to or greater than 1.2 and less than 0.83 , and the P value was less than 0.05 .

The protein ID was converted to UniProt ID, the corresponding Gene Ontology (GO) ID was obtained by searching the UniProt-GOA (www.http://www.ebi.ac.uk/GOA/) database, and GO was performed on differential protein annotations. For proteins that were not annotated, an algorithm software InterProScan (v.5.1453.0, http://www.ebi.ac.uk/interpro/) was used to predict their GO functions. Kyoto Encyclopedia of Genes and Genomes (KEGG) annotation was realized using KAAS (v.2.0, http://www.genome.jp/kaas-bin/kaas_main). KEGG Mapper (v2.5, http://www.kegg.jp/kegg/mapper.html) was used to match the gene with the pathway in the database. The two-tailed Fisher's exact test was employed to evaluate the GO or KEGG pathway enrichment.

Colony formation, Transwell, and wound-healing assays. Cells were seeded at 200 cells per well in a 6-well plate and cultured for 12 days during which DMEM was renewed every 4 days. The cells were then fixed with formaldehyde (ZhanWang Chemical, China) for $30 \mathrm{~min}$ and stained with crystal violet (Beyotime, China) for $10 \mathrm{~min}$. An inverted microscope (Olympus, Japan) was used to count the number of clones with more than 50 cells at $100 \times$ magnification.

Transwell chambers (Corning, USA) were coated with 10\% Matrigel (BD, USA). Cells were first starved with serum-free DMEM for $12 \mathrm{~h}$, and $1 \times 10^{5}$ cells were then diluted with serum-free medium and seeded in the upper chamber. Complete medium was added to the lower chamber. After a 48-h incubation, cells remaining in the upper chamber were discarded. Chambers were fixed with formaldehyde for $30 \mathrm{~min}$ and stained with crystal violet for $10 \mathrm{~min}$. Stained cells were photographed under a microscope with $200 \times$ magnification.

We plated $3 \times 10^{5}$ cells/well in a 6 -well plate and allowed the cells to grow to a density of approximately $70 \%$. A 10 ul pipette tip was used to draw a straight line in the center of each well. Scraped cells were washed off 3 times with phosphate buffered saline (PBS). Cells were then cultured and photographed at $0 \mathrm{~h}, 24 \mathrm{~h}$, and $48 \mathrm{~h}$ under a microscope with $100 \times$ magnification.

Western blot analysis. A total of $40 \mu \mathrm{g}$ of cell lysates was electrophoresed using $10 \%$ SDS-PAGE (Beyotime, China) and transferred to PVDF membranes (Millipore, USA). The membranes were blocked with 5\% skimmed milk powder for $2 \mathrm{~h}$ and then incubated with the primary antibody at $4{ }^{\circ} \mathrm{C}$ overnight. The membranes were then incubated for $1.2 \mathrm{~h}$ at room temperature with the secondary antibody conjugated to a horseradish peroxidaselabeled anti-mouse IgG (1:20,000) (Zsbio, ZB-2305). Protein bands were detected using an ECL kit (Thermo, USA) according to the manufacturer's protocol. Primary antibodies included mouse anti-PLA2G4A (1:500) (sc376618, Santa Cruz, USA) and the internal control mouse anti- $\beta$-actin (1:1000) (TA-09, Zsbio, China).

Statistical analysis. All experiments were performed in triplicate, and the data are expressed as mean \pm standard error of the mean (SEM). Image J (National Institutes of Health, USA) was used to calculate cell numbers, scratch area, and band intensity. A two-tailed t-test was conducted using Graphpad Prism 7 software (Graphpad, USA), and the Fisher's exact test was carried out using the Perl module (v.1.31, https://metacpan. org/pod/Text::NSP::Measures::2D::Fisher). P-values $<0.05$ were considered statistically significant.

\section{Data availability}

The data used to support the findings of this study are available from the corresponding author upon reasonable request. 
Received: 24 October 2020; Accepted: 2 June 2021

Published online: 15 June 2021

\section{References}

1. Thakkar, J. P. et al. Epidemiologic and molecular prognostic review of glioblastoma. Cancer Epidemiol. Biomark. 23, 1985-1996. https://doi.org/10.1158/1055-9965.EPI-14-0275 (2014).

2. Youssef, Z. et al. New targeted gold nanorods for the treatment of glioblastoma by photodynamic therapy. J. Clin. Med. 8, 2205. https://doi.org/10.3390/jcm8122205 (2019).

3. Polivka, J. J. et al. Advances in experimental targeted therapy and immunotherapy for patients with glioblastoma multiforme. Anticancer Res. 37, 21-33. https://doi.org/10.21873/anticanres.11285 (2017).

4. Ostrom, Q. T. et al. CBTRUS statistical report: Primary brain and other central nervous system tumors diagnosed in the United States in 2011-2015. Neuro Oncol. 20, iv1-iv86. https://doi.org/10.1093/neuonc/noy131 (2018).

5. Chen, L. L. Linking long noncoding RNA localization and function. Trends Biochem. Sci. 41, 761-772. https://doi.org/10.1016/j. tibs.2016.07.003 (2016).

6. Panzitt, K. et al. Characterization of HULC, a novel gene with striking up-regulation in hepatocellular carcinoma, as noncoding RNA. Gastroenterology 132, 330-342. https://doi.org/10.1053/j.gastro.2006.08.026 (2007).

7. Xiong, H. et al. LncRNA HULC promotes the growth of hepatocellular carcinoma cells via stabilizing COX-2 protein. Biochem. Biophys. Res. Commun. 490, 693-699. https://doi.org/10.1016/j.bbrc.2017.06.103 (2017).

8. Liu, T. et al. LncRNA HULC promotes the progression of gastric cancer by regulating miR-9-5p/MYH9 axis. Biomed. Pharmacother. 121, 109607. https://doi.org/10.1016/j.biopha.2019.109607 (2020).

9. Dong, Y. et al. Long non-coding RNA HULC interacts with miR-613 to regulate colon cancer growth and metastasis through targeting RTKN. Biomed. Pharmacother. 109, 2035-2042. https://doi.org/10.1016/j.biopha.2018.08.017 (2019).

10. Chu, P., Xu, L. N. \& Su, H. Y. HULC functions as an oncogene in ovarian carcinoma cells by negatively modulating miR-125a-3p. J. Physiol. Biochem. 75, 163-171. https://doi.org/10.1007/s13105-019-00669-5 (2019).

11. Yan, H. et al. High expression of long noncoding RNA HULC is a poor predictor of prognosis and regulates cell proliferation in glioma. Oncol Targets Ther. 10, 113-120. https://doi.org/10.2147/OTT.S124614 (2016).

12. Zhu, Y. et al. HULC long noncoding RNA silencing suppresses angiogenesis by regulating ESM-1 via the PI3K/Akt/mTOR signaling pathway in human gliomas. Oncotarget 7, 14429-14440. https://doi.org/10.18632/oncotarget.7418 (2016).

13. Islam, F., Gopalan, V. \& Lam, A. K. Mass spectrometry for biomarkers discovery in esophageal squamous cell carcinoma. Methods Mol. Biol. 2129, 259-268. https://doi.org/10.1007/978-1-0716-0377-2_19 (2020).

14. Zhao, Q. et al. Proteogenomics uncovers a vast repertoire of shared tumor-specific antigens in ovarian cancer. Cancer Immunol. Res. 8, 544-555. https://doi.org/10.1158/2326-6066.CIR-19-0541 (2020).

15. Deb, B. et al. Bioinformatics analysis of global proteomic and phosphoproteomic data sets revealed activation of NEK2 and AURKA in cancers. Biomolecules 10, 237. https://doi.org/10.3390/biom10020237 (2020).

16. Li, H. L. et al. Assessing the utility of multiplexed liquid chromatography-mass spectrometry for gluten detection in Australian breakfast food products. Molecules 24, 3665. https://doi.org/10.3390/molecules24203665 (2019).

17. Shao, Y. et al. Long non-coding RNA PVT1 regulates glioma proliferation, invasion, and aerobic glycolysis via miR-140-5p. Eur. Rev. Med. Pharmacol. Sci. 24, 274-283. https://doi.org/10.26355/eurrev_202008_22590 (2020).

18. Huang, W. et al. LncRNA GAS5-AS1 inhibits glioma proliferation, migration, and invasion via miR-106b-5p/TUSC2 axis. Hum. Cell. 33, 416-426. https://doi.org/10.1007/s13577-020-00331-z (2020).

19. Zhang, Q. et al. Comprehensive analysis of the long noncoding RNA expression profile and construction of the lncRNA-mRNA co-expression network in colorectal cancer. Cancer Biol. Ther. 21, 157-169. https://doi.org/10.1080/15384047.2019.1673098 (2020).

20. Cao, Y. P. et al. Long non-coding RNA in bladder cancer. Clin. Chim. Acta. 503, 113-121. https://doi.org/10.1016/j.cca.2020.01. 008 (2020).

21. Kore, R. A. \& Abraham, E. C. Inflammatory cytokines, interleukin-1 beta and tumor necrosis factor-alpha, upregulated in glioblastoma multiforme, raise the levels ofCRYAB in exosomes secreted by U373 glioma cells. Biochem. Biophys. Res. Commun. 453, 326-331. https://doi.org/10.1016/j.bbrc.2014.09.068 (2014).

22. Wu, R. et al. HMGB1 contributes to SASH1 methylation to attenuate astrocyte adhesion. Cell. Death. Dis. 10, 417. https://doi.org/ 10.1038/s41419-019-1645-7 (2019).

23. Cheng, P. J. et al. Differential proteomics analysis of amniotic fluid in pregnancies of increased nuchal translucency with normal karyotype. Prenat. Diagn. 31, 274-281. https://doi.org/10.1002/pd.2719 (2011).

24. Riedl, J. \& Ay, C. Venous thromboembolism in brain tumors: Risk factors, molecular mechanisms, and clinical challenges. Semin. Thromb. Hemost. 45, 334-341. https://doi.org/10.1055/s-0039-1688493 (2019).

25. Mathur, R. et al. MGMT promoter methylation level in newly diagnosed low-grade glioma is a predictor of hypermutation at recurrence. Neuro Oncol. https://doi.org/10.1093/neuonc/noaa059 (2020).

26. Zhang, S. C. et al. m6A demethylase ALKBH5 maintains tumorigenicity of glioblastoma stem-like cells by sustaining FOXM1 expression and cell proliferation program. Cancer Cell 31, 591-606.e6. https://doi.org/10.1016/j.ccell.2017.02.013 (2017).

27. Niu, Y. et al. RNA N6-methyladenosine demethylase FTO promotes breast tumor progression through inhibiting BNIP3. Mol. Cancer. 18, 46. https://doi.org/10.1186/s12943-019-1004-4 (2019).

28. Leslie, C. C. Cytosolic phospholipase $\mathrm{A}_{2}$ : Physiological function and role in disease. J. Lipid Res. 56, 1386-1402. https://doi.org/ 10.1194/jlr.R057588 (2015).

29. Zhao, H. Y. et al. MiR-543 promotes migration, invasion and epithelial-mesenchymal transition of esophageal cancer cells by targeting phospholipase A2 group IVA. Cell Physiol. Biochem. 48, 1595-1604. https://doi.org/10.1159/000492281 (2018).

30. Bai, H. S. et al. PLA2G4A is a potential biomarker predicting shorter overall survival in patients with non-M3/NPM1 wildtype acute myeloid leukemia. DNA Cell Biol. 39, 700-708. https://doi.org/10.1089/dna.2019.5187 (2020).

31. Tunset, H. M. et al. Cytosolic phospholipase A2 alpha regulates TLR signaling and migration in metastatic $4 \mathrm{~T} 1$ cells. Int. J. Mol. Sci. 20, 4800. https://doi.org/10.3390/ijms20194800 (2019).

32. Pang, X. et al. cPLA2a correlates with metastasis and poor prognosis of osteosarcoma by facilitating epithelial-mesenchymal transition. Pathol. Res. Pract. 215, 152398. https://doi.org/10.1016/j.prp.2019.03.026 (2019).

33. Hanahan, D. \& Weinberg, R. A. Hallmarks of cancer: The next generation. Cell 144, 646-674. https://doi.org/10.1016/j.cell.2011. 02.013 (2011).

34. Tsuji, S. et al. Temozolomide has anti-tumor effects through the phosphorylation of cPLA2 on glioblastoma cells. Brain Res. 1723, 146396. https://doi.org/10.1016/j.brainres.2019.146396 (2019).

\section{Acknowledgements}

The present study was supported by the National Natural Science Foundation of China (No.81872055 and No.81072057). 


\section{Author contributions}

J.H. put forward the idea and study design. S.Y. performed the detection experiments. J.W. and Y.W. were responsible for data searching and analysis. S.Y., Y.H., and T.Y. applied all results and prepared charts. S.Y. wrote the first draft of the manuscript. All authors read and approved the final manuscript.

\section{Competing interests}

The authors declare no competing interests.

\section{Additional information}

Supplementary Information The online version contains supplementary material available at https://doi.org/ 10.1038/s41598-021-92089-z.

Correspondence and requests for materials should be addressed to J.H.

Reprints and permissions information is available at www.nature.com/reprints.

Publisher's note Springer Nature remains neutral with regard to jurisdictional claims in published maps and institutional affiliations.

Open Access This article is licensed under a Creative Commons Attribution 4.0 International License, which permits use, sharing, adaptation, distribution and reproduction in any medium or format, as long as you give appropriate credit to the original author(s) and the source, provide a link to the Creative Commons licence, and indicate if changes were made. The images or other third party material in this article are included in the article's Creative Commons licence, unless indicated otherwise in a credit line to the material. If material is not included in the article's Creative Commons licence and your intended use is not permitted by statutory regulation or exceeds the permitted use, you will need to obtain permission directly from the copyright holder. To view a copy of this licence, visit http://creativecommons.org/licenses/by/4.0/.

(C) The Author(s) 2021 